\title{
Optimum Design of a Spur Gear Using a Two Level Optimization Approach
}

\author{
Brahim MAHIDDINI*, Taha CHETTIBI**, Khaled BENFRIHA***, Améziane AOUSSAT**** \\ *Laboratoire de Techniques Avancées de Fabrication et Contrôle, Ecole Militaire Polytechnique, Bordj El-Bahri 16111, \\ Algiers, Algeria, E-mail: Brahim.MAHIDDINI@ensam.eu \\ **Laboratoire de Mécanique des Structures, Ecole Militaire Polytechnique, Bordj El-Bahri 16111, Algiers, Algeria, \\ E-mail: tahachettibi@gmail.com \\ ***Laboratoire Conception des Produits et Innovation, Ecole Nationale Supérieure des Arts et Métiers, 151 Boulevard de \\ l'Hôpital, 75013 Paris, France, E-mail: khaled.benfriha@ensam.eu \\ ****Laboratoire Conception des Produits et Innovation, Ecole Nationale Supérieure des Arts et Métiers, 151 Boulevard \\ de l'Hôpital, 75013 Paris, France, E-mail: Ameziane.AOUSSAT@ensam.eu \\ cross $^{\text {ref }}$ http://dx.doi.org/10.5755/j01.mech.25.4.18994
}

\section{Nomenclature}

$m$ - module, mm; $b$ - face width, $\mathrm{mm} ; b_{w}$ - thickness of web, mm; $l_{w}$ - thickness of rim, $\mathrm{mm} ; Z_{1}, Z_{2}$ - number of teeth of the pinion and gear; $d_{1}, d_{2}$-diameter of pinion, gear shaft, mm; $D_{i}$ - inside diameter of rim, mm; $D_{r}$-dedendum circle diameter, $\mathrm{mm} ; d_{0}-$ outside diameter of boss, $\mathrm{mm}$; $d_{p}$-drilled hole diameter, $\mathrm{mm} ; n$ - number of drilled holes; $N_{1}, N_{2}$ - speed of pinion, gear shaft, rpm; $a$ - power rate; $P$ - power to be transmitted, Watt; $K_{0}-$ overload Factor; $K_{v}$ - dynamic factor; $K_{s}$ - size factor; $K_{H}$ - load-distribution factor; $K_{B}-$ Rim-thickness factor; $Y_{J}-$ geometry factor for bending strength; $Z_{R}-$ surface condition factor; $Z_{I}-$ geometry factor of pitting resistance; $Y_{N}$ - stress cycle factor for bending stress; $Y_{Z}$ - reliability factor; $S_{F}$ - AGMA factor of safety; $Z_{N}-$ stress cycle life factor; $Z_{W}$ - hardness ratio factors for pitting resistance; $Y_{\theta}$ - temperature factor; $S_{H}$ - AGMA factor of safety; $d$ - shaft diameter, mm; $r$ - fillet radius of keyway, mm; $D_{p}$ - pitch diameter of the pinion, mm; $Q_{v}$ - gear quality; $L-$ length of shafts, mm; $C$ - center distance, $\mathrm{mm} ; K_{b 1}, K_{b 2}$ - stress concentration factor for bending load of pinion, gear shaft; $K_{t 1}, K_{t 2}-$ stress concentration factor for torque load of pinion, gear shaft; $W^{t}$ - transmitted load, $\mathrm{N} ; M_{1}, M_{2}$ - bending moment of pinion and gear shaft, $\mathrm{Nm} ; T_{1}, T_{2}$ - torque moment of pinion, gear shaft, $\mathrm{Nm} ; t$ - depth of keyway, mm; $W$ - width of keyway, $\mathrm{mm} ; H$ - height of keyway, $\mathrm{mm} ; S_{t}$ - allowable bending stress, $\mathrm{N} / \mathrm{m}^{2} ; S_{c}-$ allowable contact stress, $\mathrm{N} / \mathrm{m}^{2}$; $\rho$-density material, gram $/ \mathrm{m}^{3} ; \sigma_{y}$ - yield strength in tension of material shafts, $\mathrm{N} / \mathrm{m}^{2} ; \alpha-$ pressure angle, degree; $Z_{E}$ - elastic coefficient; $F(x)$ - objective function; $x$ - design variable vector; $E$ - Young modulus; v - Poisson's ratio; AGMA - American gear manufacturers association; CAD - computer aided design; CAE - computer aided engineering; DoE - design of experiments; FEM - finite element method; GA - genetic algorithm; ISO - international organization for standardization; SI - system international units; SRDP - speed reducer design problem; HPSTC - highest point of single tooth contact.

\section{Introduction}

Design is an iterative intensive process due to the in- herited couplings between multiple disciplines and the overwhelming computational effort. Naturally, the probability of finding suitable design alternatives increases with the number of design iterations performed. Unfortunately, due to the requirement for shorter lead time, the number of design iterations is restricted. Thus, it is necessary to decrease the evaluation time of a design candidate in order to be able to increase the number of design iterations. Emphasis should therefore be placed on design platforms which require less evaluation time and thereby increase the chances of finding optimal products $[1,2]$.

Nowadays, it is well established that using virtual prototyping technology including CAD/CAE/CAM tools, coupled with advanced mathematical techniques such as optimization, to support designers in analyzing product performances, holds potential for shortening the overall product development cycle, improving product quality, and reducing product costs [1]. Indeed, appropriate application of these techniques during the various development phases supports design decision making based on reliable quantitative product performance data. In the present paper, we study how we can enhance the design process of a single stage spur gear based speed reducer by using these techniques.

A gear train is an essential element in various mechanical power transmission systems. It can be built in different ways according to complex design procedures which are restricted by numerous standards (ISO, AGMA and DIN) and various manufacturing processes [3]. The design process of a speed reducer is a more challenging benchmark and continues to be the focus of various research activities because of its mixed design variables. Indeed, in the specialized literature, the Speed Reducer Design Problem SRDP has been widely studied from different viewpoint and it has been solved using both stochastic and deterministic optimization techniques.

Prayoonrat and Walton [4] proposed a practical approach to optimum gear train design using a direct search method while minimizing the distance between the two shafts. Zarefar and Muthukrishnan [5] used a random search method to solve the SRDP where the weight is minimized under various constraints. Li et al [6] optimized the design of involute profile helical gears by determining the adequate geometrical factors proposed by the American standard AGMA. Yokota et al [7] formulated the SRDP as a nonlinear integer programming problem and solve it using an improved genetic algorithm. $\mathrm{Ku}$ et al [8] treated the problem using the Taguchi 
method that gives a robust design insensitive to disturbances. Rao and Xiong [9] solved a similar problem using a hybrid genetic algorithm that combines the advantages of random search and deterministic search methods to improve the convergence speed and computational efficiency. Tosserams et al [10] proposed a decomposed problem formulation based on the augmented Lagrangian penalty function and the block coordinate descent algorithm for quasi-separable multidisciplinary design optimization problems. Cagnina et al. [11] developed a particle swarm optimization algorithm to solve various constrained engineering optimization problems including SRDP. Jaberipour and Khorram [12] suggested two harmony search metaheuristic algorithms for engineering optimization problems with continuous design variables and applied their method also to solve the SRDP. Savsani et al. [13] implemented two optimization techniques, particle swarm optimization and simulated annealing, to find the parameters that optimize the weight of the reducer, satisfying some design constraints. Lu and Kim [14] proposed a decomposition algorithm for multidisciplinary design optimization problems with complementarily constraints based on the regularization technique and inexact penalty decomposition; it was successfully applied for solving SRDP. Marjanovic et al. [15] developed a multistep optimal design approach of spur gear train leading to the optimum values of transmission ratio and center distance between shafts. In [16], a deterministic approach, based on convexification strategies and piecewise linearization methods, is applied to globally solve the one-stage speed reducer design problem. Golabi et al. [17] optimized the weight of a gear train with one, two and three stages, and they used optimization techniques available in the optimization Toolbox of Matlab ${ }$. In [18], Rao considered the minimum weight design problem of a spur gear train using the Teaching Learning Based Optimization Algorithm while considering various constraints.

The analysis of the previous cited references shows that most of the proposed approaches for the treatment of SRDP are based on the utilization of analytical models to evaluate the performances of any design candidate. In contrast, there are few works that make use of finite element models to optimize the design of spur gear trains. Beghini et al. [19] proposed a simple method to reduce the transmission error, by means of the profile modification. Indeed, they used a method combining the finite element method and semi analytical solution. In another work, Korta and Mundo [20] aimed to find optimal microgeometry modifications of tooth profile of a pair of identical spur gears, providing decreased values of peak-topeak transmission error and maximal contact stress along the meshing cycle. They used three kinds of metamodeling techniques: the Gaussian Process (stochastic), the Shepard k-Nearest (non parametric deterministic) and the Polynomial (parametric deterministic). Wan et al. [21] optimized the power split device by proposing a multi-objective optimization method to achieve optimal balance solution among the volume, contact stress and frictional energy dissipation. They use the finite element method FEM to compute the nonlinear responses and adapted a surrogate model in order to find best values of the design variables.

The analysis of references [4-21] highlights a common fact that the proposed design approaches employ exclusively one type of models, analytical or numerical (i.e. FEM) one, to evaluate the performances of any design candidate. This model is generally integrated in a tailored optimization procedure. Hereafter, we present a two level optimization approach in order to enhance the design process of a one-stage spur gear based speed reducer. The proposed design methodology enables fast and efficient design optimization of the reducer by combining judiciously the use of analytical models and FEM based models for evaluating the performances of any design candidate. The proposed approach is expected to drastically decrease the number of iterations required to obtain good designs. It consists of a two-level optimization procedure that replaces the computationally expensive classical design approach.

To gain speed, analytical models are used in the first design level. After that, higher fidelity CAD-CAE models are introduced in the second level. However, in order to minimize evaluation time and to allow time efficient optimization processes, metamodel-based optimization is adopted in this second level. These models are built according to a DoE set up around the suboptimal design obtained in the first level. It is worth noting that, at this level; the dimension of the search space can be enlarged or reduced according to the requirement of the designer. Also additional performance criteria or constraints can be included to refine the design.

\section{Problem description}

The problem concerns the optimum design of a simple speed reducer which is described in Fig.1. It is a common mechanical device able to transmit power with accuracy between two shafts and it has various applications in industry. Hereafter, we are concerned with the minimum weight design problem of one stage spur gear train while considering constraints inherent mainly to:

- bending strength of pinion and gear teeth;

- contact stress (surface durability);

- torsional strength of pinion and gear shafts;

- distance between pinion and gear shafts.

The main design variables are: $x=\left(b, d_{1}, d_{2}, Z_{1}, m\right)$

- face width $b$,

- diameters of pinion and gear shafts $\left(d_{1}, d_{2}\right)$,

- the number of teeth $Z_{1}$ of the pinion,

- gear module $m$.

Note that $Z_{1}$ is an integer and $m$ should take discrete values.

\section{Proposed approach}

In this paper, a two-level design optimization approach is introduced to solve the considered SRDP. The proposed design process is illustrated in Fig.2.The first level is based on using an analytical model which is considered as a low cost computation model. In fact, evaluation time using analytical models is usually short and the design freedom associated with these models is generally high. Therefore, the application of global optimization techniques associated with these models is an efficient way to investigate good designs. Also the optimization should be performed using a technique able to handle mixed variables.

In the second level, the suboptimal solution obtained at the end of the first level is used to construct a fine $\mathrm{CAD}$ model of the reducer. After that, a design of experiments DoE is judiciously established according to optimum design parameters obtained at this first level. Then, appropriate metamodels (surrogate models) are built using powerful CAE tools. It is worth noting that it is possible at this second level to add new design variables and to include complementary studies in order to refine properly the considered design. Once metamodels are constructed, efficient 
optimization techniques can be then applied in order to find the optimum design.

In order to be able to handle mixed variables and to avoid the problem being stacked in local minima, we have used a genetic algorithm GA to solve the considered SRDP.
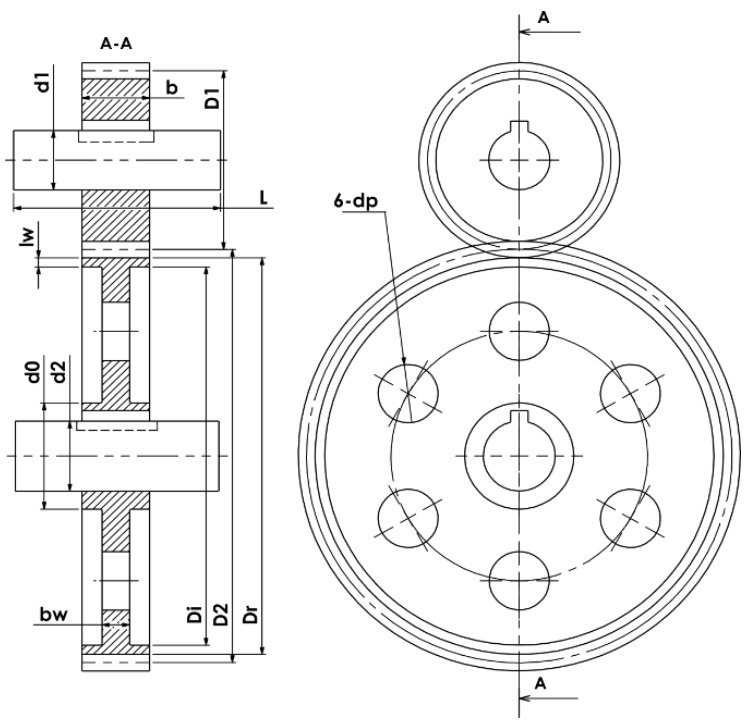

Fig. 1 The geometry of a one-stage speed reducer

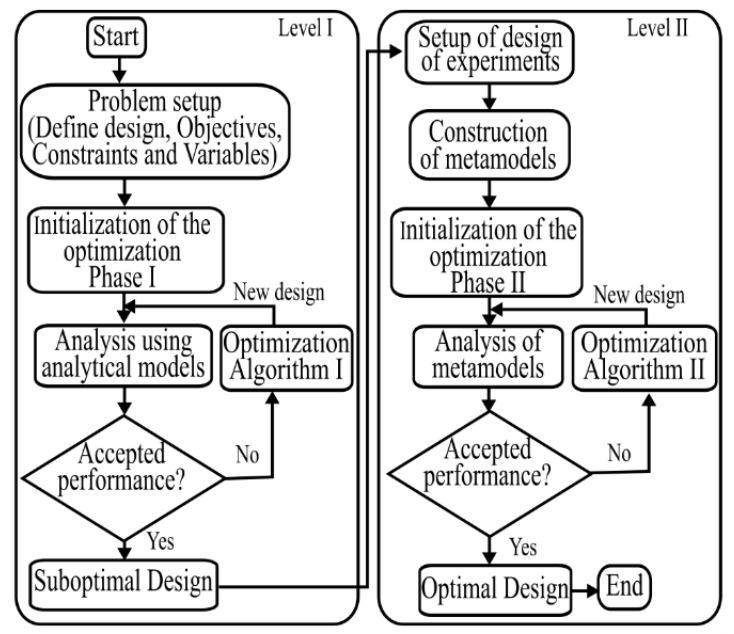

Fig. 2 The proposed design approach based on a two levels optimization strategy

\subsection{Genetic algorithm description}

The optimization algorithm adopted in level I and level II is a Genetic Algorithm GA. It is briefly introduced hereafter. GA is a heuristic method, which is based on natural selection, the process that drives biological evolution [22]. GA starts by generating a population of individuals in the space search. The choice of the size of population and the manner for representing the individual solutions are very important in order to promote the success of the method. For example, by using binary numbers, each individual solution is coded as a finite fixed length string (chromosome). Then, each individual solution is evaluated by calculating the objective function values. Hence, each string is assigned a fitness value which is established in accordance with the objective function values. Thus, at each cycle, GA selects individuals at random from the current population to be parents and uses them to generate the children for the next generation. Over successive generations, the population evolves toward an optimal solution that approximates the global optimum with a high probability [23]. This makes GA popular and widely used in different domains of engineering, science and economic [24].

Fundamentally, GA uses three main types of rules at each step to create the next generation from the current population [25]:

- Selection: Selection rules select the individuals (called parents) that contribute to the population at the next generation. According to the fitness value, the selection operator eliminates the candidate solutions, which have a poor fineness and retains those have an acceptable fitness, in order to enter them in the reproduction process.

- Crossover: Crossover rules combine two parents to form children for the next generation. The goal is to create new solution candidates by exchanging information between two or more solutions.

- Mutation: The mutation rules change randomly the binary digit 1 to 0 and vice versa of a string obtained after reproduction and crossover operators. They apply random changes to individual parents to form new children.

A key operator of GAs is the reproduction operator dedicated to identify and select good solutions in a population, with elimination of bad solutions and replacing by various copies of good solutions, without changing the population size [26].

In order to solve the optimization problems addressed in Level I and Level II, we used the genetic algorithm available under the Global Optimization Toolbox of Matlab $\AA$, by using the following parameters:

- Crossover Fraction=0.6,

- Migration Fraction=0.1,

- Population Size=250,

- Number of generations=500.

\subsection{Description of the first level}

The first level corresponds in fact to the preliminary design of our product. During this phase, designers try to explore faster the space design while sizing the target product, in respect of the main technical and economic criteria. Thus, analytical formulation is introduced at this stage, in order to evaluate quickly the main performances of the design candidates.

In this study, we developed the first level using the model of reference [7], which is based on the AGMA standards [27]. Also, we introduced several modifications concerning: correction factors, material choices for gears and transmission shafts. Finally, the considered design problem is set up as a nonlinear constrained mono-objective optimization problem with mixed variables. The elements of this problem are:

i) Objective function to be minimized is:

$$
\begin{aligned}
& F(x)=\left(\pi \rho_{\text {gear }} / 4\right)\left(b m^{2} Z_{1}^{2}\left(1+a^{2}\right)-\left(D_{i}^{2}-d_{0}^{2}\right)\left(b-b_{w}\right)-\right. \\
& \left.-n d_{p}^{2} b_{w}-\left(d_{1}^{2}+d_{2}^{2}\right) b\right)+\left(\pi \rho_{\text {shaft }} / 4\right)\left(d_{1}^{2} L+d_{2}^{2} L\right)
\end{aligned}
$$

ii) Constraints to be satisfied are:

$$
g_{1}(x)=W^{t} K_{0} K_{v} K_{s} \frac{1}{b m} \frac{K_{H} K_{B}}{Y_{J}} \leq \frac{S_{t}}{S_{F}} \frac{Y_{N}}{Y_{\theta} Y_{Z}}
$$




$$
\begin{gathered}
g_{2}(x)=Z_{E}\left(W^{t} K_{0} K_{v} K_{s} \frac{K_{H}}{D_{p} b} \frac{Z_{R}}{Z_{I}}\right)^{1 / 2} \leq \frac{S_{c}}{S_{H}} \frac{Z_{N} Z_{W}}{Y_{\theta} Y_{Z}}, \\
g_{3}(x)=d_{1}^{3} \geq\left(32 / \pi \sigma_{y}\right)\left(\left(K_{b 1} M_{1}\right)^{2}+\left(K_{t 1} T_{1}\right)^{2}\right)^{\frac{1}{2}}, \\
g_{4}(x)=d_{2}^{3} \geq\left(32 / \pi \sigma_{y}\right)\left(\left(K_{b 2} M_{2}\right)^{2}+\left(K_{t 2} T_{2}\right)^{2}\right)^{\frac{1}{2}}, \\
g_{5}(x)=(1+a) m Z_{1} / 2 \leq C .
\end{gathered}
$$

where: $g_{1}(x)$ is for bending strength of tooth; $g_{2}(x)$ is for surface durability; $g_{3}(x)$ and $g_{4}(x)$ are for torsion strength of shafts for pinion and gear, respectively; $g_{5}(x)$ is for the center distance.

Note that $g_{1}(x)$ and $g_{2}(x)$ are constraints for bending strength of pinion tooth and for surface durability (pitting resistance) respectively. Note that Yokota et al. [7] used simplified formulations for $g_{1}(x)$, and $g_{2}(x)$ in their works. Authors considered that the dynamic factor $K_{v}$ is constant. However, $K_{v}$ is variable and depends of pitch line velocity $V$ (Eq. (7)). Hereafter, more precise formulations for $K_{v}, K_{t}, K_{b}$ respectively dynamic, torsional and bending stress concentration factors are used [28]:

$$
\begin{aligned}
& K_{v}=\left(\left(59.773+(200 V)^{0.5}\right) / 59.773\right)^{0.8255}, \\
& K_{t}=1.953+0.1434\left(0.1 \frac{d}{r}\right)-0.0021\left(0.1 \frac{d}{r}\right)^{2}, \\
& K_{b}=1.426+0.1643\left(0.1 \frac{d}{r}\right)-0.0019\left(0.1 \frac{d}{r}\right)^{2} .
\end{aligned}
$$

where: $r$ is the filet radius and $d$ is the shaft diameter as shown in Fig.3.

iii) Design vector is $x=\left(b, d_{1}, d_{2}, Z_{1}, m\right)$ where each component varies within specific limits:

$$
\begin{array}{ll}
25 \leq b \leq 40 & 20 \leq d_{1} \leq 40 \\
20 \leq d_{2} \leq 40 & 18 \leq Z_{1} \leq 25 \text { (Integer) }
\end{array}
$$

$m=(2.5,2.75,3,3.5,4)$

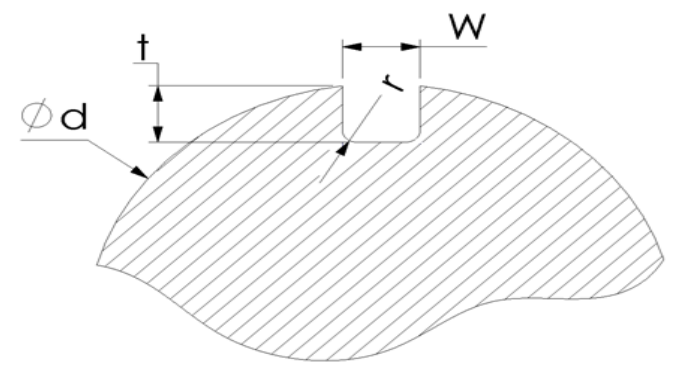

Fig. 3 Geometric parameters involved in the shaft's concentration constraint

The Table 1 summarizes data being used in the first level for solving the optimization problem. The obtained suboptimal solution of this first level is given in Table 2 .
Data used in level I

Table 1

\begin{tabular}{|c|c|c|}
\hline$a=4$ & $n=6$ & $D_{0}=d_{2}+25$ \\
\hline$P=7500$ & $L=100$ & $D_{r}=m\left(\mathrm{a} Z_{1}-2.5\right)$ \\
\hline$N_{1}=1500$ & $Q_{v}=6$ & $D_{i}=D_{r}-2 l_{w}$ \\
\hline$D_{2}=a D_{1}$ & $b_{w}=3.5 m$ & $d_{p}=0.25\left(D_{i}-d_{0}\right)$ \\
\hline$l_{w}=205 m$ & $D_{1}=m Z_{1}$ & $C=140$ \\
\hline \multicolumn{2}{|c|}{$K_{0}=1, K_{H}=1, K_{s}=1, K_{B}=1, Z_{R}=1, Y_{J}=0.325$} \\
$Z_{E}=1.9044 \mathrm{E} 5, Y_{\theta}=1, S_{H}=1, S_{F}=1, Y_{Z}=1, Z_{N}=0.95$ \\
$Z_{W}=1, Z_{I}=0.1286, Y_{N}=0.98, Y_{Z}=0.85, Y_{T}=1$ \\
\hline \multicolumn{2}{|c|}{ Gear material:17NiCrMo6 } & Shafts material: C45 \\
$E=2.1 \mathrm{E} 11$ & $E=2.1 \mathrm{E} 11$ \\
$v=0.28$ & $v=0.28$ \\
$\rho_{\text {gear }}=7.8 \mathrm{E} 6, S_{t}=224,16 \mathrm{E} 6$, & $\rho_{\text {shaft }}=7.8 \mathrm{E} 6$ \\
$S_{c}=766.77 \mathrm{E} 6$ & $\sigma_{y}=380 \mathrm{E} 6$ \\
\hline
\end{tabular}

Table 2

Solution of the first level

\begin{tabular}{|c|c|}
\hline Parameters & Value \\
\hline$b$ & 36.5904 \\
\hline$d_{1}$ & 22.9419 \\
\hline$d_{2}$ & 25.6013 \\
\hline$Z_{1}$ & 22 \\
\hline$m$ & 2.5 \\
\hline Optimum weight & 5059.14 gram \\
\hline
\end{tabular}

\subsection{Description of the second level}

Practically, this second level corresponds to the detailed design phase and it starts from the solution obtained in the first level. Indeed, precise modelling tools such as CAD-CAE tools are used herein order to refine the obtained design and to improve specific performances. Thus, it is possible to reevaluated the design in regards of new parameters so, new regions of the design space are explored. Also, advanced aspects which have been ignored at the first level or it was impossible to handle using traditional analytical models are now deeply studied. In consequence, if CADCAE tools are properly used, higher fidelity models are accessible and they bring more knowledge about the considered product through advanced studies using particularly FEM based modules. However, in order to minimize the evaluation time and to allow time efficient optimization process, response surface methods involving design of experiments DoE and Radial basis functions RBF, should be applied.

RBF have been developed basically in order to fit scattered multivariate data [29]. In the framework of surface response methodology, $\mathrm{RBF}$ are considered as an excellent method to fit a surface to a set of deterministic data obtained using computer simulation codes. Indeed, the use of this method is recommended when the number of design variables increases and the responses (approximated functions) are highly nonlinear. The method uses linear combinations of a radially symmetric function based on Euclidean distance [30]. The form of a RBF interpolation can be written as follows:

$$
f(x)=\sum_{1}^{N} a_{i} \varphi\left(x-x_{i}\right)+b x+c,
$$

where: $x_{i}$ is a point of the adopted DoE, $\|$.$\| indicates the Eu-$ clidian norm and $a_{i}$ is a real value. The radial basic function 
$\varphi$ can take many forms (linear, cubic, multiquadric, Gaussian, ...). The solution of Eq. (10) allows to determinate the unknown parameters $a_{i}$ for $i=1, \ldots, N, b$ and $c$, by solving the following linear equations system:

$$
\left[\begin{array}{cc}
\Phi & \mathbf{q} \\
\mathbf{q}^{T} & 0
\end{array}\right]\left\{\begin{array}{l}
\mathbf{a} \\
\mathbf{d}
\end{array}\right\}=\left\{\begin{array}{l}
\mathbf{F} \\
0
\end{array}\right\},
$$

where: $\Phi$ is a $(N \times N)$ square matrix, its elements are obtained by $\Phi_{i, j}=\varphi\left\|x_{i}-x_{j}\right\|$.

$$
\mathbf{q}=\left[\begin{array}{cc}
1 & x_{1}^{T} \\
\vdots & \vdots \\
1 & x_{N}^{T}
\end{array}\right], \mathbf{a}=\left\{\begin{array}{c}
a_{1} \\
\vdots \\
a_{N}
\end{array}\right\}, \mathbf{d}=\left\{\begin{array}{c}
c \\
b_{1} \\
\vdots \\
b_{N}
\end{array}\right\}, \mathbf{F}=\left\{\begin{array}{c}
f\left(x_{1}\right) \\
\vdots \\
f\left(x_{N}\right)
\end{array}\right\} .
$$

\section{Validation of metamodels}

The validation of metamodels is necessary before implementing it in the optimization process [31]. There are several metrics in the literature to verify the accuracy of metamodels, in this part we have used two measures that are the root mean square error (RMSE) and the maximum absolute error (MAE), are defined below:

$$
\begin{aligned}
& \mathrm{RMSE}=\sqrt{\frac{\sum_{i=1}^{N}\left(y_{i}-\hat{y}_{i}\right)^{2}}{N}}, \\
& \mathrm{MAE}=\max \left(\left|y_{1}-\hat{y}_{1}\right|,\left|y_{2}-\hat{y}_{2}\right|, \ldots,\left|y_{N}-\hat{y}_{N}\right|\right) .
\end{aligned}
$$

where: $N$ is the number of validation points; $\hat{y}_{i}$ is the predicted point and $y_{i}$ is the true value. The more accurate of the metamodel corresponds of the lower value of RMSE and RAE.

In the present work, we used SolidWorks ${ }^{\circledR}$ as a design tool and a framework to conduct FEM studies using it powerful toolbox Simulation.

Firstly, we used the "Equation" function in order to create a parametric design model of the spur gear system, taking into account all desired design parameters and accounting for the results of the first level. Indeed, analytical formulation of the first level is able to provide an acceptable suboptimal solution within a reduced computation time. However, it does not give access to a complete CAD model with sufficient details, particularly in several critical zones. In the second level, thanks to CAD tools, we get access to all details of a virtual prototype of the considered product. Therefore, evaluating the desired performances in critical areas is an easy task. Moreover, new design parameters are introduced in the CAD model such as: thickness of the rim, thickness of the web and the drilled hole diameter (Fig.4). In consequence, the size of the new design vector becomes eight (versus 5 in the $1^{\text {st }}$ level).

Secondly, the computation procedure described in Fig. 5 is then applied, it can be summarized in the following three points:

i) Setting up the space design in the vicinity of the suboptimal solution found in the first level. This permits to reduce the size of DoE and to improve the quality of constructed metamodels. Table 3 indicates the adopted limits of our design space. After that and using Matlab ${ }^{\circledR}$, we generate a Hypercube Latin Sampling (LHS) design of experiments. This DoE is more adapted to construct RBF based metamodels which are exclusively adopted in this phase. After that, the generated DoE is exported to SolidWorks ${ }^{\circledR}$ through an Excel File.

ii) After importing the generated DoE in Solidworks ${ }^{\circledR}$, numerical experiences are conducted using the design study of Solidworks ${ }^{\circledR}$ Simulation ${ }^{\circledR}$ tool [32]. Specific sensors were created for assessing objective function and constraints using adequate static studies, these studies are briefly explained bellow. The obtained results are then exported to Matlab ${ }^{\circledR}$ through an Excel file.

iii) Construction of seven RBF metamodels in Matlab ${ }^{\circledR}$. Thus, a new optimization problem can be formulated and solved by using also the genetic algorithm. The optimal design is then obtained and verified.

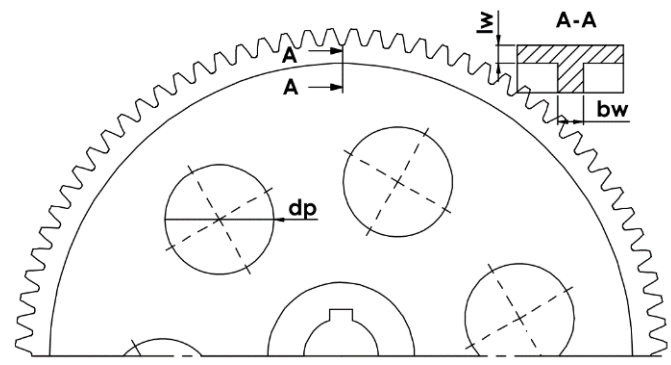

Fig. 4 The three design parameters added in Level II

The second level leads to the optimum design of Table 4. We see that the weight has been decreased considerably about $(20.83 \%)$.

The static studies employed in the second level to evaluate the desired performances are now briefly described:

Static study 1. This study permits to assess two kinds of constraints: bending stress of the pinion tooth and the Hertz pressure (corresponding respectively to constraints $g_{1}$ and $g_{2}$ of the 1 st level). For that, we developed a finite element model (Fig.6) according to references [33-36]. It is based on the choice of the contact position, where the bending stress of the pinion tooth and the contact pressure are maximized; it represents a single contact point in the line of action (HPSTC). The mesh's type and the element's size are very important for evaluating the Hertz pressure in the contact region. In order to check the validity of the model, we achieved a comparative study between obtained FEM solution, the Lewis formula, the Hertz theory and the AGMA standard; results are given in Table 7, according to this table, the results obtained by the FE method are near to those obtained by the AGMA standard (for $K_{h}=1$ ). In order to validate our FE model used in this study, we realized various tests of comparisons.

Static study 2 and 3. The purpose of these static studies is to evaluate the von Mises constraints in the pinion and gear shafts respectively, under the stress concentration effect in the keyway. These studies correspond to the constraints $g_{3}$ and $g_{4}$ of the first level, by introducing also bending in vertical and horizontal plans, due to radial and tangential forces. On the basis of references [37-43], we built another FEM model and set up the limit conditions as shown in Fig. 6.The dimensions of the used key are given in Table 
6 according to the standard ISO R773 [44]. Table 7 presents a comparison of the first level solution, the Maximum Shear Stress Theory (MSST) results and that obtained by FEM of pinion and gear shafts, in the face of the similarity of the results obtained by the two methods (FEM and MSST), several tests carried out to verify the accuracy of our FE model used.

Static study. The geometrical modification of the wheel may reduce the weight of the product, but it can affect negatively its rigidity. For this, we introduce two additional constraints in the optimization problem, the first represents bending strength of the gear tooth $g_{6}$ and the second corresponds to the constraint in the web $g_{7}$. A new FEM model corresponding to this study has been built as shown in Fig.8. It represents a critical configuration in which both constraints are maximized, this configuration corresponds to a single contact point in the line action and the angle between the hole axis and the contact tooth is equal to $10^{\circ}$ (Fig.9).

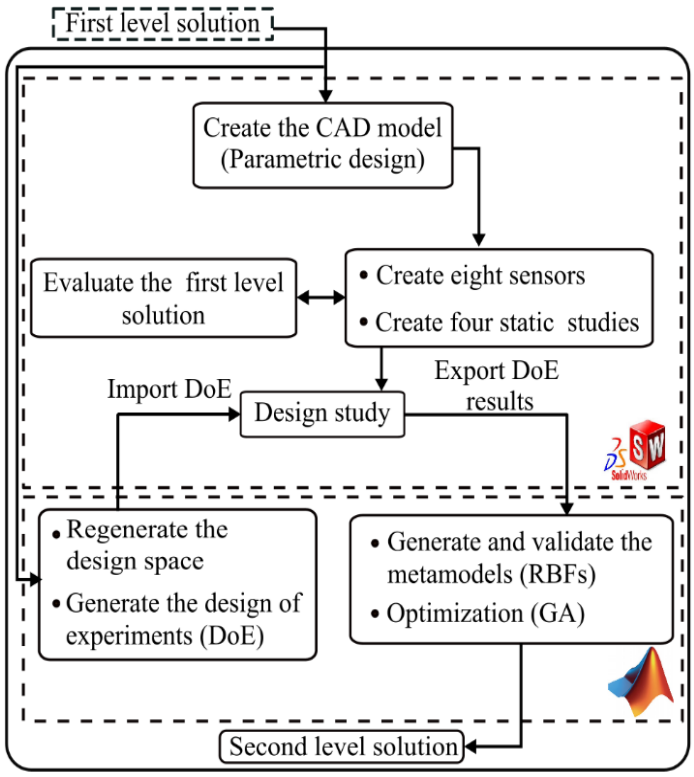

Fig. 5 The second level computation approach

Table 3

The new design space of the second level

\begin{tabular}{|c|}
\hline $35.5 \leq b \leq 37.5$ \\
\hline $22.1 \leq d_{1} \leq 24.1$ \\
\hline $24.5 \leq d_{2} \leq 26.6$ \\
\hline $21 \leq Z_{1} \leq 23$ \\
\hline$m=(2.5,2.75)$ \\
\hline $5.25 \leq l_{w} \leq 7.25$ \\
\hline $7.75 \leq b_{w} \leq 9.75$ \\
\hline $49 \leq d_{p} \leq 57$ \\
\hline
\end{tabular}

Table 4

Solution of the second level

\begin{tabular}{|c|c|}
\hline Parameters & Value \\
\hline$b$ & 35.7495 \\
\hline$d_{1}$ & 22.853 \\
\hline$d_{2}$ & 25.8654 \\
\hline$Z_{1}$ & 22 \\
\hline$m$ & 2.5 \\
\hline$l_{w}$ & 6.2004 \\
\hline$b w$ & 8.2535 \\
\hline$d p$ & 56.3689 \\
\hline Optimum weight & 4005.44gram \\
\hline
\end{tabular}

Table 5

Evaluation and comparison of the first level solution

\begin{tabular}{|c|c|c|}
\hline & $\begin{array}{c}\text { Bending stress of the } \\
\text { pinion tooth }\end{array}$ & Hertz pressure \\
\hline $\begin{array}{c}\text { Analytical } \\
\text { formula }\end{array}$ & $\begin{array}{c}61.416 \mathrm{MPa} \\
\text { (Lewis formula) }\end{array}$ & $\begin{array}{c}493.3 \mathrm{MPa} \\
\text { (Hertz theory) }\end{array}$ \\
\hline AGMA & $175.488 \mathrm{MPa}$ & $855.174 \mathrm{MPa}$ \\
\hline FEM & $56.1497 \mathrm{MPa}$ & $462.84 \mathrm{MPa}$ \\
\hline
\end{tabular}

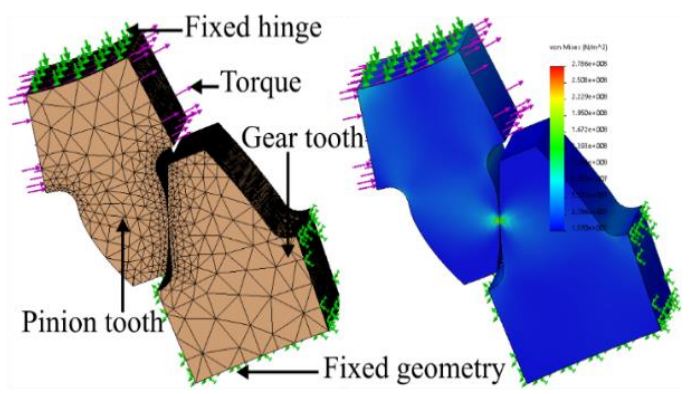

Fig. 6 The FEM model adopted for evaluating the tooth bending strength and contact pressure

Table 6

Keyway dimensions used in the studies

\begin{tabular}{|c|c|c|c|c|c|}
\hline \multicolumn{2}{|c|}{ Nominal shaft diameter } & \multirow{2}{*}{$W$} & $H$ & $t$ & $r$ \\
\hline Over & To (Inclus.) & & & & \\
\hline 17 & 22 & 6 & 6 & 3.5 & 0.25 \\
\hline 22 & 30 & 8 & 7 & 4 & 0.25 \\
\hline
\end{tabular}

Table 7

Comparison between MSST and FEM results

\begin{tabular}{|c|c|c|}
\hline & $\begin{array}{c}\text { Pinion shaft } \\
\text { (von Mises stress) }\end{array}$ & $\begin{array}{c}\text { Gear shaft } \\
\text { (von Mises stress) }\end{array}$ \\
\hline MSST & $152.660 \mathrm{MPa}$ & $331.560 \mathrm{MPa}$ \\
\hline FEM & $133.596 \mathrm{MPa}$ & $347.685 \mathrm{MPa}$ \\
\hline
\end{tabular}

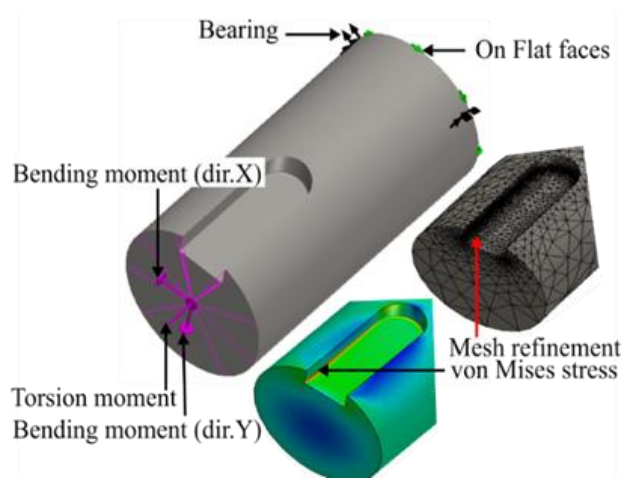

Fig. 7 The FEM model adopted for evaluating the von Mises constraint in the pinion and gear shafts

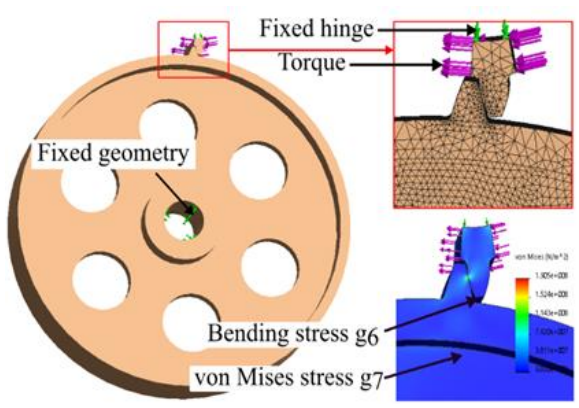

Fig. 8 The FEM model adopted for evaluating the gear tooth bending strength and the web von Mises constraint 


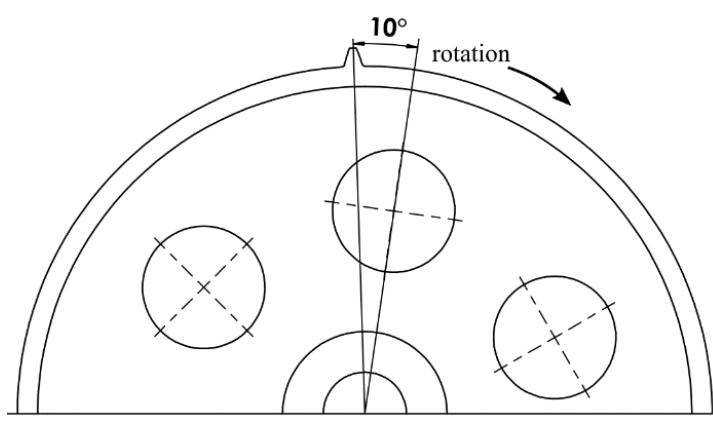

Fig. 9 Angle between the hole and tooth corresponding to the maximum constraint in the web

\section{Discussion}

The optimization of a product by implementing this approach, allows improving the product performances and its design process at the same time. In order to evaluate the performances of two solutions obtained, a comparative study was made, using SolidWorks software. The simulation results show the importance of associating the analytical optimization of the product by a second advanced optimization, introducing metamodels techniques and CAD/CAE tools. According to Fig. 10, the performances of the second solution are acceptable and check the constraints of the optimization problem. Nevertheless, some degradation of certain performances appears as the deflection of the tooth.

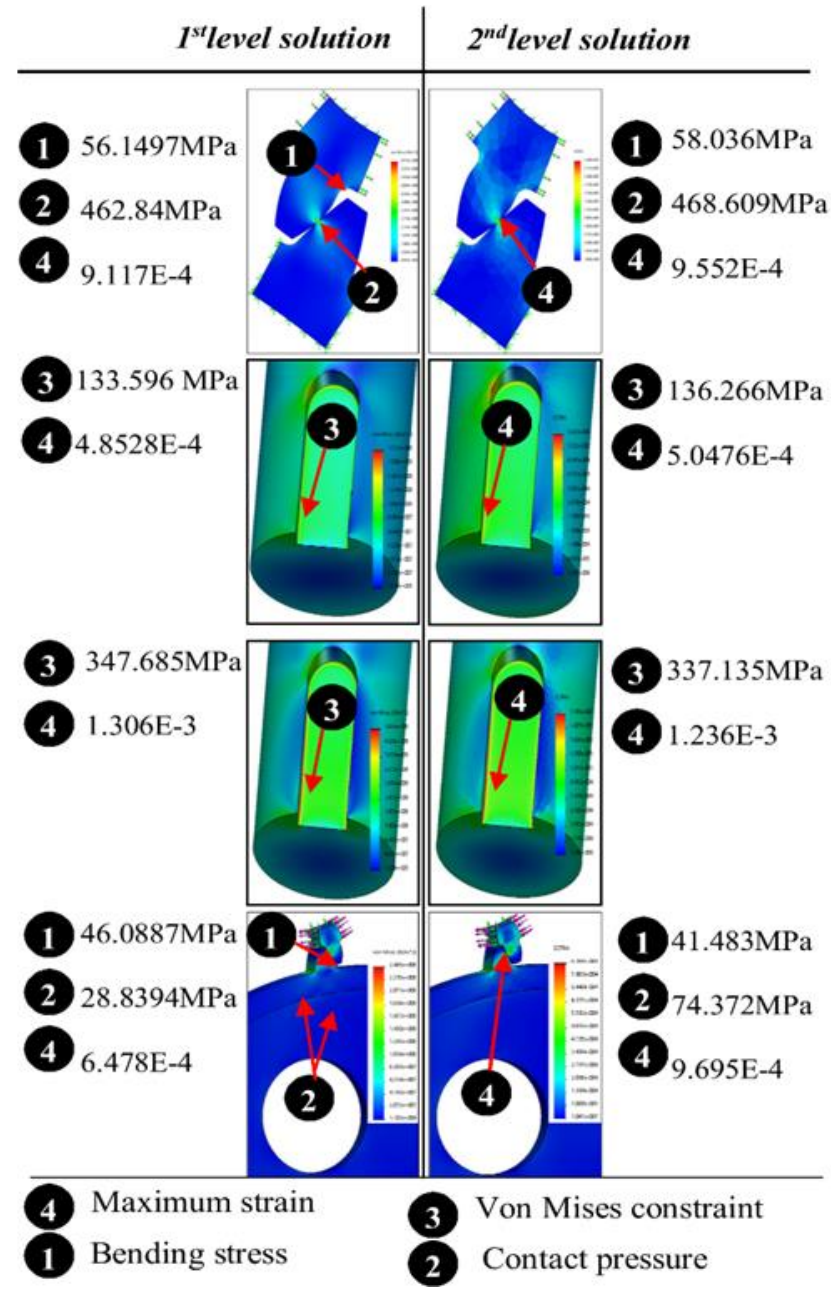

Fig. 10 FEM based Comparison between solutions of the first and the second level

\section{Conclusion}

In this paper, we presented a two level design optimization methodology for a simple reducer. The first level is based on using an analytical formulation of the design problem based on classical gear and beam theory. Thus, we rapidly explored the design space while accounting for standards to set up correcting factors and applying safety factors. However, this leads in general to an oversized product. In order to improve the optimization process, we followed this first level by a second one that uses CAD/DAE tools. By utilizing the design of experiments and metamodels techniques, we constructed suitable approximations of the objective function and the constraints. This second level was able to reduce considerably the weight of our system. The obtained results are better than those existing in many papers dealing with a similar system.

The proposed approach enhances the traditional design approaches based only on analytical models by adding a refinement phase based on metamodels. Also, modern design techniques are made more efficient by starting the design process, within CAD-CAE environment, from feasible solutions obtained using traditional (analytical) techniques. The proposed method can be easily extended for other mechanical power transmission systems, mechanisms and machines for which simple analytical (1D) models and complex numerical (3D) models are available.

\section{References}

1. Chang, K. H. 2014. Design Theory and Methods using CAD/CAE. -Amsterdam: Academic Press. 516 p.

2. Masataka, Y. 2010. System Design Optimization for Product Manufacturing.-London, UK: Springer-Verlag. $200 \mathrm{p}$.

3. Henriot, G. 2013. Engrenages - Conception - Fabrication - Mise en œuvre.- Paris, France: DUNOD. 912 p. (in French).

4. Prayoonrat, S.; Walton, D. 1988. Practical approach to optimum gear train design, Computer-Aided Design 20(2): 83-92.

https://doi.org/10.1016/0010-4485(88)90053-X.

5. Zarefar, H.; Muthukrishnan, S. N. 1993. Computeraided optimal design via modified adaptive randomsearch algorithm, Computer-Aided Design 25(4): 240248. https://doi.org/10.1016/0010-4485(93)90055-S.

6. Li, X.; Symmons, G. R.; Cockerham, G. 1996. Optimal design of involute profile helical gears, Mechanism and Machine Theory 31(6): 717-728. https://doi.org/10.1016/0094-114X(95)00080-I.

7. Yokota, T.; Taguchi, T.; Gen, M. 1998. A solution method for optimal weight design problem of the gear using genetic algorithms, Computers \& Industrial Engineering 35(3): 523-526. https://doi.org/10.1016/S0360-8352(98)00149-1.

8. Ku, K. J.; Rao, S. S; Chen, L. 1998. Taguchi-aided search method for design optimization of engineering systems, Engineering Optimization 30(1): 1-23. https://doi.org/10.1080/03052159808941235.

9. Rao, S. S.; Xiong, Y. 2004. Hybridgenetic algorithm for mixed-discrete design optimization, Journal of Mechanical Design 127(6): 1100-1112. https://doi.org/10.1115/1.1876436. 
10. Tosserams, S.; Etman, L. F. P.; Rooda, J. E. 2007. An augmented Lagrangian decomposition method for quasiseparable problems in MDO, Structural and Multidisciplinary Optimization 34(3): 211-227. https://doi.org/10.1007/s00158-006-0077-z.

11. Cagnina, L. C.; Esquivel, S. C.; Coello, C. A. C. 2008. Solving engineering optimization problems with the simple constrained particle swarm optimizer, Informatica 32(3): 319-326.

12. Jaberipour, M.; Khorram, E. 2010. Two improved harmony search algorithms for solving engineering optimization problems, Communications in Nonlinear Science and Numerical Simulation 15(11): 3316-3331. https://doi.org/10.1016/j.cnsns.2010.01.009.

13. Savsani, V.; Rao, R.V.; Vakharia, D.P. 2010. Optimal weight design of a gear train using particle swarm optimization and simulated annealing algorithms, Mechanism and Machine Theory 45(3): 531-541.

https://doi.org/10.1016/j.mechmachtheory.2009.10.010.

14. Lu, S.; Kim, H.M. 2010. A regularized inexact penalty decomposition algorithm for multidisciplinary design optimization problems with complementarily constraints, Journal of Mechanical Design, 132(4): 12p. https://doi.org/10.1115/1.4001206.

15. Marjanovic, N.; Isailovic, B.; Marjanovic, V.; Milojevic, Z.; Blagojevic, M.; Bojic, M. 2012. A practical approach to the optimization of gear trains with spur gears, Mechanism and Machine Theory 53: 1-16. https://doi.org/10.1016/j.mechmachtheory.2012.02.004.

16. Lin, M. H. ; Tsai, J. F. ; Hu, N. Z. ; Chang, S. C. 2013. Design Optimization of a Speed Reducer Using Deterministic Technique, Mathematical Problems in Engineering 2013: 1-7. http://dx.doi.org/10.1155/2013/419043.

17. Golabi, S.; Fesharaki, J.J.; Yazdipoor, M. 2016. Gear train optimization based on minimum volume/weight design, Mechanism and Machine Theory 73: 197-217. https://doi.org/10.1016/j.mechmachtheory.2013.11.002.

18. Rao, R.V. 2016. Teaching Learning Based Optimization Algorithm and Its Engineering Applications, -Switzerland: Springer International Publishing. 284p.

19. Beghini, M.; Presicce, F.; Santus, C. 2004. A Method to Define Profile Modification of Spur Gear and Minimize the Transmission Error, American Gear Manufacturers Association: 1-9.

20. Korta, J.A.; Mundo, D. 2017. Multi-objective microgeometry optimization of gear tooth supported by response surface methodology, Mechanism and Machine Theory 109: 278-295. https://doi.org/10.1016/j.mechmachtheory.2016.11.015.

21. Wang, J.; Shen, W.; Wang, Z.; Yao, M.; Zeng, X. 2014. Multi-objective optimization of drive gears for power split device using surrogate models, Journal of Mechanical Science and Technology 28(6): 2205-2214. https://doi.org/10.1007/s12206-014-0509-4.

22. Du, K. L.; Swamy, M. N. S. 2016. Search and Optimization by Metaheuristics Techniques and Algorithms Inspired by Nature. -Switzerland: Birkhäuser Basel. 434p.

23. Yang, X.S. 2014. Nature-Inspired Optimization Algorithms. -Amsterdam, Netherlands: Elsevier Inc. 300p.

24. Bhoskar, M. T.; Kulkarni, K. O. K.; Kulkarni, M. N. K.; Patekar, M. S. L.; Kakandikar, G. M.; Nanded- kar, V. M. 2015. Genetic Algorithm and Its Applications to Mechanical Engineering. A Review, Materialstoday: Proceedings 2(4): 2624-2630.

https://doi.org/10.1016/j.matpr.2015.07.219.

25. Messac, A. 2015. Optimization in Practice with MATLAB ${ }^{\circledR}$ for Engineering Students and Professionals. -New York, NY: Cambridge University Press. 469p.

26. Deb, K. 1999. An introduction to genetic algorithms, Sādhanā 24(4): 293-315. https://doi.org/10.1007/BF02823145.

27. Budynas, R. G.; Nisbett, J. K. 2008. Shigley's Mechanical Engineering Design $9^{\text {th }}$ edition. -New York, USA: McGraw-Hill. 1120p.

28. Pilkey, W. D.; Pilkey, D. F. 2008. Peterson's Stress Concentration Factors $3^{\text {rd }}$ edition. - Hoboken, New Jersey: John Wiley \& Sons, Inc. 560p.

29. Park, H. S. ; Dang, X. P. 2010. Structural optimization based on CAD-CAE integration and metamodeling techniques, Computer-Aided Design 42 (10): 889-902. https://doi.org/10.1016/j.cad.2010.06.003.

30. Jin, R.; Chen, W., Simpson, T. W. 2001. Comparative studies of metamodelling techniques under multiple modelling criteria, Struct. Multidisc. Optim 23(1): 1-13. https://doi.org/10.1007/s00158-001-0160-4.

31. Wang, G. G.; Shan, S. 2007. Review of Metamodeling Techniques in Support of Engineering Design Optimization, Journal of Mechanical Design 129(4): 370-380. https://doi.org/10.1115/1.2429697.

32. Weber, M.; Verma, G. 2015 Solidworks simulation 2015 black book, USA : CADCAMCAEWORKS. 400p.

33. Jabbour, T.; Asmar, G. 2015 Tooth stress calculation of metal spur and helical gears, Mechanism and Machine Theory 92: 375-390. https://doi.org/10.1016/j.mechmachtheory.2015.06.003.

34. Li, S. 2007. Finite element analyses for contact strength and bending strength of a pair of spur gears with machining errors, assembly errors and tooth modifications, Mechanism and Machine Theory 42 (1): 88-114. https://doi.org/10.1016/j.mechmachtheory.2006.01.009.

35. Gonzalez-Perez, I.; Iserte, J. L.; Fuentes, A. 2011. Implementation of Hertz theory and validation of a finite element model forstress analysis of gear drives with localized bearing contact, Mechanism and Machine Theory 46(6): 765-783. https://doi.org/10.1016/j.mechmachtheory.2011.01.014.

36. Roda-Casanova, V.; Sanchez-Marin, F. T.; Gonzalez-Perez, I. ; Iserte, J. L. ; Fuentes, A. 2013. Determination of the ISO face load factor in spur gear drives by the finite element modeling of gears and shafts, Mechanism and Machine Theory 65: 1-13.

https://doi.org/10.1016/j.mechmachtheory.2013.02.006.

37. Pedersen, N. L. 2010. Stress concentrations in keyways and optimization of keyway design, Journal of Strain Analysis for Engineering Design 45(8): 593-604. https://doi.org/10.1243/03093247JSA632.

38. Muminovic, A. J.; Saric, I.; Repcic, N. 2015. Numerical Analysis of Stress Concentration Factors, Procedia Engineering 100: 707-713. https://doi.org/10.1016/j.proeng.2015.01.423.

39. García-Masiá, C.; Ceresa, P.; Morillas-Álvarez, J. D. 2006. Modeling and analysis of a power transmission system: influences in tooth contact analysis of the gears, 
Proceeding. ASME $8^{\text {th }}$ Biennial Conference on Engineering Systems Design and Analysis, Torino, Italy: 137-141.

40. Vasile, C.; Ovidiu, C. A. 2014 Finite element analysis of stresses distributions on the shafts and the housing of a helical gear reducer, Journal of Industrial Design and Engineering Graphics 9(1): 5-8.

41. Pardhi, D. G.; Khamankar, S. D. 2014 Stress analysis of spline shaft using finite element method and its experimental verification by photo elasticity, International Journal of Mechanical Engineering and Robotics Research 3(4): 451-458.

42. Prajapati, H. R.; Patel, B. P. ; Patel, N. V. 2015. Investigation of Stress Concentration Factor for Keyway on Shaft under Different Loading Conditions: A Case [online]. Available from Internet : http://www.ganpatuniversity.ac.in.

43. Le, X.; Le, Z. 2013. Stress concentration factors due to typical geometric discontinuities for shaft, Proceeding. 2013 ASEE Annual Conference \& Exposition, Atlanta, Georgia, USA: 1-16.

44. Erik, O.; Franklin, J. D.; Holbrook, H. L.; Ryffel, H. H. 2008. Machinery's Handbook \& Guide to Machinery's Handbook $28^{\text {th }}$ edition. - New York, NY: Industrial Press Inc. 2704 p.
B. Mahiddini, T. Chettibi, K. Benfriha, A. Aoussat

OPTIMUM DESIGN OF A SPUR GEAR USING A TWO LEVEL OPTIMIZATION APPROACH

\section{S u m m a r y}

In this paper, we present a two level optimization approach in order to enhance the design process of a one-stage speed reducer. The proposed design methodology is performed using genetic algorithms which are judiciously combined with the use of: i) analytical models ( $1^{\text {st }}$ level) and ii) Finite Element Method (FEM) based models ( $2^{\text {nd }}$ level), to evaluate design candidates. Indeed, the use of CAD-CAE tools to develop higher fidelity FEM models allows to re-evaluate the attained first level designs, while accounting for new design parameters and advanced aspects which have been ignored in the first level. In order to minimize the computational burden, a metamodel based optimization technique is adopted at this second level. To illustrate the efficiency of the proposed approach, a case study of a spur gear based reducer is presented where the design of experiments is built using Hypercube Latin Sampling and surrogate models are constructed using Radial Basic Functions.

Keywords: spur gear, genetic algorithm, metamodel, optimum design. 